\title{
Nova ocorrência de Manihot jolyana Cruz (Euphorbiaceae) para o estado do Rio de Janeiro, Brasil
}

\author{
Sabrina Queiroz de Farias \\ Universidade Federal do Rio de Janeiro, Museu Nacional, Programa de Pós-Graduação em Ciências Biológicas (Botânica), \\ Departamento de Botânica, Quinta da Boa Vista s/n, São Cristóvão, CEP 20.940-040, Rio de Janeiro, RJ, Brasil. \\ fariassq@gmail.com
}

Recebido em 09.02.2019

Aceito em 04.X.2019

DOI 10.21826/2446-82312019v74e2019015

\begin{abstract}
RESUMO - Manihot jolyana é referida pela primeira vez para o estado do Rio de Janeiro. A espécie foi registrada no município de Petrópolis durante o estudo de Euphorbiaceae s.s. no Parque Nacional da Serra dos Órgãos, desenvolvido entre os anos de 2015 e 2017. São apresentados descrição, comentários taxonômicos, dados sobre habitat e distribuição geográfica, mapa de distribuição, floração e frutificação e imagens da espécie.
\end{abstract}

Palavras-chave: flora, Mata Atlântica, Petrópolis, Serra do Mar, taxonomia

ABSTRACT - New occurrence of Manihot jolyana Cruz (Euphorbiaceae) for the Rio de Janeiro state, Brazil. Manihot jolyana is referred for the first time for Rio de Janeiro state. The species was registered in the municipality of Petrópolis during the study of Euphorbiaceae s.s. in the Serra dos Órgãos National Park, conducted between 2015 and 2017. Description, taxonomic comments, data on the habitat and geographical distribution, map of distribution, flowering and fruiting and images of the species are provided.

Keywords: Atlantic Forest, flora, Petrópolis, Serra do Mar, taxonomy

\section{INTRODUÇÃO}

Manihot Mill. é um dos gêneros da subfamília Crotonoideae, tribo Manihoteae pertencente à família Euphorbiaceae. É nativo das regiões tropicais e subtropicais do continente americano (Rogers \& Appan 1973), com aproximadamente 120 espécies, a maioria (ca. 103) ocorrendo no Brasil (Silva et al. 2019, Flora do Brasil 2020). As espécies de Manihot são reconhecidas pela presença de látex, folhas usualmente lobadas, flores monoclamídeas, as estaminadas com 10 estames em duas classes de altura, as pistiladas com ramos estigmáticos ornamentados, frutos capsulares, costados ou lisos e sementes carunculadas (Rogers \& Appan 1973, Webster 1994), além de raízes geralmente tuberosas, ricas em carboidratos, como é o caso de M. esculenta Crantz, popularmente conhecida como "mandioca", "mandioca-braba", "mandioca-brava", "manioca", "aipim" ou "macaxeira", amplamente utilizada na alimentação (Olsen \& Schall 1999). Apesar de Manihot ser um gênero monofilético e facilmente reconhecido, possui taxonomia complexa decorrente, principalmente, de seus táxons apresentarem plasticidade morfológica foliar, homogeneidade floral e frequente hibridização natural, o que resulta em sobreposição em suas morfologias e dificulta suas identidades taxonômicas (Rogers \& Appan 1973, Allem 1977, 1979a, b, Duputié et al. 2011, Silva \&
Sodré 2014). As principais obras clássicas que trataram à taxonomia de Manihot foram realizadas por Pohl (1827), Müller (1866, 1874), Pax (1910) e Rogers \& Appan (1973). Estes últimos autores publicam uma monografia revisional para o gênero, distribuindo suas espécies em 19 seções. Estas, apesar de não terem o seu monofiletismo corroborado nos trabalhos filogenéticos (Chacón et al. 2008, Deputié et al. 2011), são as mais aceitas atualmente.

No Brasil, a alta diversidade do gênero está associada a regiões secas, sendo o bioma do Cerrado, o principal centro de diversidade do grupo. No entanto, há também espécies tipicamente ocorrentes em florestas, onde habitam em áreas de vegetação mais aberta (Rogers \& Appan 1973, Allem 1999, Deputié et al. 2011, Silva \& Sodré 2014). De acordo com a Flora do Brasil (2020) Manihot é reconhecido por 17 espécies para o domínio da Mata Atlântica, sendo sete citadas para o Rio de Janeiro: M. caerulescens Pohl, $M$. corymbiflora Pax \& K. Hoffm., M. inflata Müll. Arg., M. leptopoda (Müll.Arg.) D.J. Rogers \& Appan, M. pilosa Pohl, M. pohlii Wawra e M. tripartita (Spreng.) Müll. Arg. No presente trabalho, M. jolyana Cruz. é registrada pela primeira vez no Rio de Janeiro, durante o estudo de Euphorbiaceae s.s. no Parque Nacional da Serra dos Órgãos, desenvolvido entre 2015 e 2017. Desta forma, aumentase para oito o número de espécies do gênero no estado e amplia-se a distribuição geográfica conhecida da espécie. 


\section{MATERIAL E MÉTODOS}

As informações apresentadas neste trabalho resultam de exemplares obtidos em expedições de campo na região serrana do estado do Rio de Janeiro, além de consultas realizadas nos principais herbários fluminenses FCAB, GUA, HB, R, RB, RBR, RFA e RFFP, estrangeiros C, F, G, K, M, P, FLAS, NMNH e NY (acrônimos de acordo com Thiers et al. 2019) e na base de dados e imagens digitais do SpeciesLink 2017.

As amostras coletadas foram processadas conforme as técnicas usuais em herborização sugeridas por Mori et al. (1985) e posteriormente depositadas no herbário R, com duplicatas enviadas ao herbário RB. A identificação taxonômica foi estabelecida com base na descrição original (Cruz 1965, 1967), literatura especializada (Allem 1980, Rogers \& Appan 1973), comparações com as coleções dos herbários, fotos e imagens dos materiais-tipo da espécie. As descrições morfológicas foram baseadas apenas nos exemplares examinados. A terminologia adotada nas descrições das estruturas vegetativas e florais seguiu Rogers \& Appan (1973) e Radford et al. (1974). As fitofisionomias utilizadas na designação dos locais de ocorrência da espécie seguiu Veloso et al. (1991). O mapa de distribuição foi confeccionado no Software Qgis versão 2.14.

\section{RESULTADOS E DISCUSSÃO}

Manihot jolyana Cruz Bragantia 24: 360. 1965.

Manihot handroana Cruz, Bragantia 26: 318. 1967.

(Figs. 1A-J)

Arbustos: 1,7-5 m alt., eretos, látex leitoso; caules cilíndricos, lenhosos, verde-escuros a marrons; ramos pubescentes, verde-claros quando jovens, glabros e acinzentados, quando adultos.

Folhas: alternas, pecioladas, simples, 5-7-lobadas, raramente, 6- ou 9-lobadas, membranáceas, camptódromas, face adaxial glabrescente ou pubescente, tricomas simples esparsamente distribuídos, face abaxial pubescente ou tomentosa, tricomas simples uniformemente distribuídos ou pouco mais abundante sobre as nervuras; lobos 11-18 x 4,4$7,5 \mathrm{~cm}$, oboval-elípticos ou obovais, às vezes pandurados, inteiros, sobrepostos na base, ápice acuminado ou cuspidado; pecíolo 5-28 cm compr., pubescente, inserido na base da lâmina; estípula 13-30 x 1-2 mm compr., filiforme, linear ou linear-lanceolada, densamente pubescente, margem inteira ou dentado-glandulosa, precocemente caduca. Panículas 15-21 cm compr., congestas, bissexuais, terminais, eretas, pubescentes; flores pendentes dispostas em um só lado do eixo floral da raque; brácteas não vistas, bractéola na base do pedicelo, 8-15 x 3-5 mm, lanceolada, ápice longamente acuminado, caduca na antese, foliácea, curvada sobre o botão, pubescente externamente, bractéolas 2 , na metade do pedicelo, 4-5 x 1,2-1,7 mm, lanceoladas, ápice longamente acuminado, pubescentes externamente.
Flores estaminadas: 28-38 mm compr., pedicelo 7-14,5 mm compr., botões 22,3-32 mm compr., cônicos; cálice gamossépalo, campanulado, verde-amarelado a purpúreo externamente, roxeado internamente, lobos 23,5-29 x 7-10 $\mathrm{mm}$, oval-oblongos, ápice agudo, indumento próximo da margem, disco 10-lobado amarelo-alaranjado, estames 10, glabros, em duas séries de altura, cinco externos maiores, cinco internos menores, anteras 4-4,5 mm compr., filetes 5,5-17 mm compr. Flores pistiladas: $34-35 \mathrm{~mm}$ compr., pedicelo $16,5 \mathrm{~mm}$ compr., cálice dialissépalo, campanulado, verde-amarelado a purpúreo externamente, roxeado internamente, botões 11-12,5 mm compr., sépalas 20-21 x 7-7,1 mm, oval-oblongas, ápice agudo, indumento próximo da margem, disco lobado amarelo-alaranjado, ovário globoso, liso, glabro, esverdeado, estiletes 3 , unidos na base, com ramos estigmáticos franjados.

Cápsulas: 21,6-24 x 20,9-23 mm, globosas, trígonas em seção transversal, lisas, glabras, esverdeadas; sementes 12,8-14,3 x 10,5-11 mm, oblongoides, amareladas a marrons, maculadas, carúncula amplamente triangular, creme a amarelada. Ilustração em Cruz $(1965,1967)$.

Material examinado: BRASIL. RIO DE JANEIRO, Petrópolis, rodovia BR-495, Estrada Philuvio Cerqueira Rodrigues, $22^{\circ} 25^{\prime} 06.3^{\prime} \mathrm{S}, 43^{\circ} 03^{\prime} 05.1^{\prime \prime} \mathrm{W}, 1.225 \mathrm{~m}$, 9.XII.2016, fl. fr., S.Q. Farias \& J.L. Silva 182 (R); I.2017, fr., S.Q. Farias \& J.L. Silva 201 (R, RB); 22 $25^{\circ} 05^{\prime}$ 'S, 4303'10.65"W, I.2017, st., S.Q. Farias \& J.L. Silva

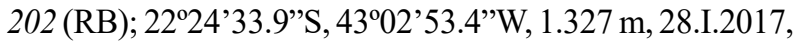
fr., S.Q. Farias \& J.L. Silva 206 (R); 30.XI.2017, fl., S.Q. Farias \& J.L. Silva 222 (R, RB); 8.XII.2017, fr., S.Q. Farias \& J.L. Silva 224 (R, RB); 8.XII.2017, fl., S.Q. Farias \& J.L. Silva 226 (R, RB); 2.IV.2018, fr., S.Q. Farias \& J.L. Silva 237 (RB); Araras, 4.II.1974, fr., G. Martinelli \& D. Sucre 201 (RB); rodovia RJ-117, Estrada Almirante Paulo Meira, entrada de acesso para a trilha Morro do Cuca, 30.XI.2017, fr., S.Q. Farias \& J.L Silva 218 (R); trilha para o Morro do Cuca, 22 25'35'S, 43 '17'01.6”'W, 1.073 m, 26.X.2017, fl., S.Q. Farias \& J.L. Silva s.n. (R 236616); 30.XI.2017, fr., S.Q. Farias \& J.L. Silva 217 (R); rodovia RJ-117, Estrada Almirante Paulo Meira, 22 25'34.6”S, $43^{\circ} 15^{\prime} 31.8^{\prime} \mathrm{W}, 1.083$ m, 30.XI.2017, fl., fr., S.Q. Farias \& J.L. Silva 219 (R); 30.XI.2017, fl., S.Q. Farias \& J.L.

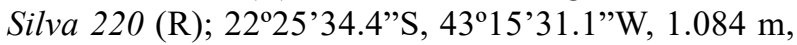
30.XI.2017, fr., S.Q. Farias \& J.L. Silva 221 (R); Vale das Videiras, $950-1.200 \mathrm{~m}$ de altitude, 6/7.I.1974, fr., D. Sucre et al. 10621 (RB); Morro do Cuca, 1.500 m, 22.XI.1977, fr., G. Martinelli 3551 (RB).

Manihot jolyana é endêmica do Brasil e restrita ao domínio fitogeográfico da Mata Atlântica. Ocorre em Minas Gerais e São Paulo, na Serra da Mantiqueira (Cruz 1965, 1967), onde se desenvolve em áreas de capoeira e beira de estrada, entre 1.250 e $1.600 \mathrm{~m}$ de altitude. No Rio de Janeiro foi localizada no município de Petrópolis (fig. 2), no entorno de duas Unidades de Conservação: Parque Nacional da Serra dos Órgãos e Reserva Biológica de Araras, ambas 



Figs. 1A-J. Manihot jolyana. A. mata de galeria; B. populações em mata de encosta; C. hábito; D. ramo fértil; E. inflorescência; F. estípulas; G. base da lâmina mostrando os lobos sobrepostos; H. flor estaminada em vista frontal; I. ramo mostrando o látex; J. fruto. (fotos: S.Q. Farias). 


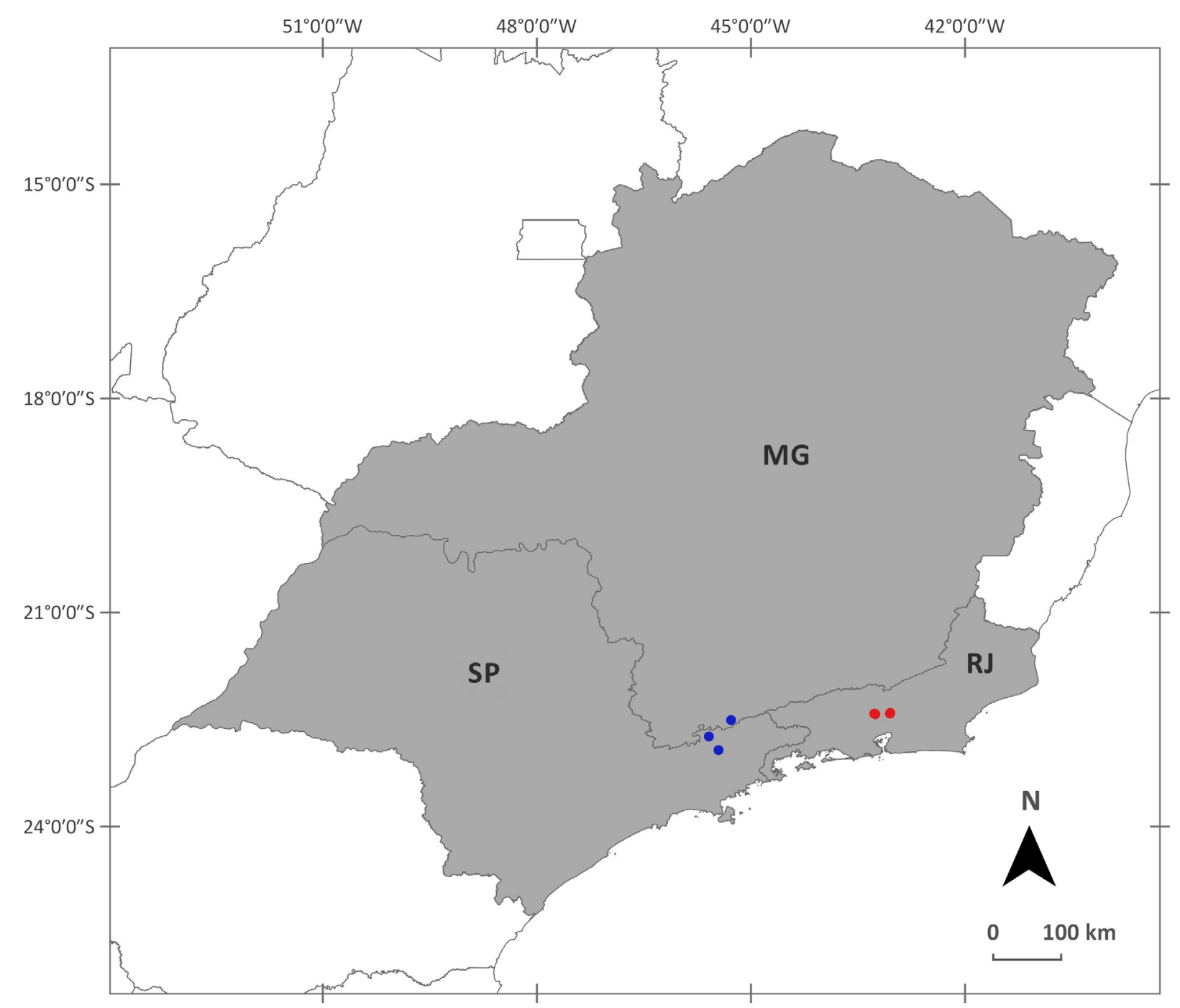

Fig. 2. Mapa de distribuição de Manihot jolyana nos estados de Minas Gerais (MG), São Paulo (SP)(círculos azuis) e nova ocorrência para o Rio de Janeiro (RJ), município de Petrópolis (círculos vermelhos).

inseridas na Serra do Mar. A espécie habita formação de Floresta Ombrófila Densa Montana, entre 950 e 1.500 $\mathrm{m}$ de altitude, formando pequenas populações (até 10 indivíduos), em bordas de matas de galerias e de encostas, em ambientes parcialmente sombreados a ensolarados, tendo sido registrada na trilha para o Morro do Cuca e na Rodovia RJ-117, entre o Vale das Videiras e Araras, e na Rodovia BR-495, entre Teresópolis e Itaipava. Floresce de outubro a janeiro, e frutifica de novembro a abril.

De acordo com a classificação de Rogers \& Appan (1973), Manihot jolyana pertence à seção Heterophyllae, a qual se caracteriza por espécies de hábito frequentemente arbustivo, com folhas pecioladas amplamente espaçadas no caule, lâminas membranáceas lobadas, lobos inteiros a pandurados, pecíolos comumente aderidos na base da lâmina, panículas monoicas e brácteas e bractéolas foliáceas a setáceas com margem inteira. Dentre as espécies da seção, M. jolyana destaca-se, principalmente, pela pubescência nos ramos e nas folhas, sobreposição dos lobos da lâmina na base, inflorescências em panículas ramificadas, congestas e bem desenvolvidas e flores pendentes densamente dispostas em um só lado do eixo floral da raque.

Cruz (1967) relacionou M. jolyana e $M$. handroana Cruz, na obra original desta última, como espécies muito próximas geográfica, genética e morfologicamente, no entanto afirmou serem distinguíveis em suas características vegetativas e reprodutivas, separando $M$. jolyana de $M$. handroana pela pilosidade mais densa no ápice dos ramos e na face adaxial das lâminas, lobos da lâmina com ápice acuminado quase cuspidado ( $v s$. cuspidado em $M$. handroana), maior dimensão na junção entre os lobos da lâmina, estípulas maiores, 23 x 1,5 mm com margem dentado-glandulosa ( $v s .12 \times 0,8 \mathrm{~mm}$ com margem inteira), bractéolas maiores, 5-7 mm compr. (vs. 2-4 mm compr.), sépalas estaminadas menores, $20-21 \mathrm{~mm}$ compr. (vs. 25 $\mathrm{mm}$ compr.), sépalas pistiladas menores, $15 \mathrm{~mm}$ compr. (vs. 18-20 mm compr.) e frutos circulares em seção transversal ( $v s$. acentuadamente trígonos). Rogers \& Appan (1973), na 
revisão da Flora Neotropica, comentaram a grande afinidade morfológica entre $M$. jolyana e $M$. handroana, sugerindo uma investigação mais minuciosa entre estes táxons em estudos futuros, porém os consideraram como espécies distintas, utilizando o comprimento e pubescência das lâminas, largura da base dos lobos medianos e superfície dos frutos para separá-los. Segundo os mesmos autores, $M$. jolyana teria folhas com mais de $12,5 \mathrm{~cm}$ compr, (vs. com menos de 12,5 cm compr. em $M$. handroana), base dos lobos acima de $0,5 \mathrm{~cm}$ larg. (vs. menos de $0,5 \mathrm{~cm}$ larg.), lâminas densamente pubescentes (vs. moderamente pubescentes) $\mathrm{e}$ superfície dos frutos não alada (vs. alada). Allem (1980), ao revisar algumas espécies da seção Heterophyllae, colocou $M$. handroana como sinônimo de M. jolyana, afirmando que ambas eram conspecíficas. O referido autor desconsiderou os caracteres utilizados por Rogers \& Appan (1973) na separação dos táxons, e comentou que o maior e menor grau de pubescência e dimensões das folhas não têm qualquer valor taxonômico para as espécies, e após analisar as descrições, ilustrações e materiais-tipo de $M$. handroana, deixou claro a interpretação equivocada dos autores ao atribuírem caráter alado à superfície do fruto desta espécie, sendo o mesmo de superfície lisa, semelhante ao observado em M. jolyana. Segundo Allem, os frutos só teriam valor diagnóstico se as suas superfícies fossem distintas. Recentemente, Orlandini \& Lima (2014) ao publicarem a sinopse de Manihot para o Estado de São Paulo, propuseram uma sinonimização de $M$. handroana sob M. jolyana, no entanto, tal sinonimização já havia sido feita formalmente por Allem (1980).

Durante observações intensas de populações em campo e análise de exemplares da região, verificaram-se espécimes com características sobrepostas e intermediárias a $M$. jolyana e $M$. handroana, tornando-se praticamente impossível diferenciá-los. A única característica que se manteve conservada foi a forma trígona dos frutos em seção transversal, conforme descrita por Cruz (1967) para os frutos de M. handroana. Entretanto, este caráter isolado não é suficiente para justificar o táxon como entidade distinta, além de não ser utilizado nas delimitações infragenéricas de Manihot. Este trabalho, portanto, concorda com as observações e a sinonimização estabelecida por Allem (1980), uma vez que, não existem subsídios de valor taxonômico para a separação de $M$. handroana de $M$. jolyana.

Cruz (1965) e Rogers \& Appan (1973) também referiram $M$. jolyana como uma espécie semelhante a $M$. pohlii. No entanto, Cruz (1965) diferenciou M. jolyana pela pilosidade, comprimento do pecíolo, forma e número de lobos da lâmina, maior densidade e comprimento das flores nos racemos, diferenças no comprimento entre as flores estaminadas e pistiladas e maior comprimento do pedicelo das flores. Enquanto, Rogers \& Appan (1973) separaram M. jolyana pelo maior grau de ramificação e comprimento das inflorescências, maior largura dos lobos da lâmina e sobreposição dos lobos da lâmina na base.
Allem (1980), por sua vez, assemelhou M. jolyana a M. tomentosa Pohl, espécie da seção Grandibracteatae, separando-as apenas pela superfície dos frutos, que em $M$. jolyana é glabra, enquanto em $M$. tomentosa é pubescente. No entanto, incluem-se como principais características adicionais na diferenciação destas espécies, o tipo e o maior comprimento das inflorescências, panículas 15-30 $\mathrm{cm}$ em M. jolyana ( $v s$. racemos 5-10 cm), ápice dos lobos da lâmina, acuminado a cuspidado em M. jolyana ( $v s$. agudo a obstuso), sobreposição dos lobos da lâmina na base, presente em M. jolyana (vs. ausente) e consistência das lâminas, membranácea em M. jolyana (vs. coriácea). Além disso, ambas as espécies possuem distribuição e domínios fitogeográficos diferentes, M. jolyana ocorre em Minas Gerais, São Paulo e Rio de Janeiro, na Mata Atlântica, enquanto $M$. tomentosa, em Goiás e Minas Gerais, no Cerrado.

Este estudo contribuiu com a atualização de distribuição geográfica de M. jolyana. No entanto, ressalta-se a necessidade de mais esforços de coletas para avaliar adequadamente a delimitação do referido táxon, além de estudos florístico-taxonômicos de Manihot na região serrana do Rio de Janeiro para um melhor conhecimento do gênero e de sua diversidade na flora do estado e da Mata Atlântica.

\section{AGRADECIMENTOS}

Ao Sr. José Lúcio da Silva, técnico do Museu Nacional, da Universidade Federal do Rio de Janeiro, pelo auxílio nas excursões e reencontro das plantas em campo; ao Prof. Dr. Jorge Fontella Pereira, da mesma instituição, pela concessão das bibliografias; aos curadores e técnicos dos herbários visitados pela permissão para consulta das coleções; ao Instituto Brasileiro do Meio Ambiente e dos Recursos Naturais Renováveis e ao Parque Nacional da Serra dos Órgãos (PARNASO) pelo apoio logístico e licença de coleta concedida; ao Conselho Nacional de Desenvolvimento Científico e Tecnológico pela concessão de bolsa de mestrado (Proc. no. 831012/1999-4).

\section{REFERÊNCIAS}

Allem, A.C. 1977. Notas taxonômicas e novos sinônimos em espécies de Manihot - I (Euphorbiaceae). Revista Brasileira de Biologia 37(4):825-835.

1979a. Notas taxonômicas e novos sinônimos em espécies de Manihot - III (Euphorbiaceae). Revista Brasileira de Biologia 39(3): 545-550.

1979b. Notas taxonômicas e novos sinônimos em espécies de Manihot - IV (Euphorbiaceae). Revista Brasileira de Biologia 39(4):735-738.

1980. Notas taxonômicas e novos sinônimos em espécies de Manihot - VI (Euphorbiaceae). Boletim do Museu Botânico Municipal de Curitiba 40: 1-14.

1999. A new species of Manihot (Euphorbiaceae) from the Brazilian Amazon. International Journal of Plant Sciences 160: 181-187.

Chacón, J., Madriñán, S., Debouck, D., Rodriguez, F. \& Tohme, J. 2008. Phylogenetic patterns in the genus Manihot (Euphorbiaceae) inferred 
from analyses of nuclear and chloroplast DNA regions. Molecular Phylogenetics and Evolution 49(1): 260-267.

Cruz, N.D. 1965. Nova espécie do gênero Manihot Adans. do Estado de São Paulo. Bragantia 24: 360.

. 1967. Nova espécie do gênero Manihot Adans. do Estado de Minas Gerais. Bragantia 24: 311-328.

Duputié, A., Salick, J. \& McKey, D. 2011. Evolutionary biogeography of Manihot (Euphorbiaceae), a rapidly radiating Neotropical genus restricted to dry environments. Journal of Biogeography 38: 10331043.

Flora do Brasil 2020 (em construção). Jardim Botânico do Rio de Janeiro. Disponível em: http://floradobrasil.jbrj.gov.br. Acessado em 15.09.2019.

Mori, S.A., Silva, L.A.M., Lisboa, G. \& Coradin, L. 1985. Manual de manejo do herbário fanerogâmico. Centro de Pesquisa do Cacau, Olhéus. $119 \mathrm{p}$.

Müller, A. 1866. Euphorbiaceae exceto subordo Euphorbieae. In Prodromus Systematics Universalis Regni Vegetabilis (A.P. De Candolle, ed.) v.15, p. 189-1286.

1874. Euphorbiaceae. In Flora Brasiliensis (C.F.P. Martius \& A.G. Eichler, eds.) v. 11, p. 1269-1286.

Olsen, K.M. \& Schall, B.A. 1999. Evidence on the origin of cassava: Phylogeography of Manihot esculenta. Proceedings of the National Academy of Sciences of the United States of America 96(10): 5586-5591.

Orlandini, P. \& Lima, L.R. 2014. Sinopse do gênero Manihot Mill. (Euphorbiaceae) no Estado de São Paulo, Brasil. Hoehnea 41(1): 51-60.
Pax, F. 1910. Euphorbiaceae-Manihot Adans. In Das Pflanzenreich IV. Euphorbiaceae-Adrianeae (A. Engler, ed.). Konigl Preuss Akademie der Wissenschaften, Leipizig, v. 147, p. 21-111.

Pohl, J. 1827. Manihot Adans. In Plantarum Brasiliae icones et descriptiones. Typis et charta Antonii Strauss, Viena. v.1, p. 17-56.

Radford, A.E., Dickison, W.C., Massey, J.R. \& Bell, C.R. 1974. Vascular plants systematics. Harper \& Row, New York. 891p.

Rogers, D.J. \& Appan, S.G. 1973. Manihot, Manihotoides (Euphorbiaceae). Flora Neotropica 13:1-272.

Silva, M.J. \& R.C. Sodré. 2014. A dwarf species of Manihot Mill. (Euphorbiaceae s.s.) from the highlands of Goiás, Brazil. Systematic Botany 39: 222-226.

Silva, M.J., Souza, A.O., Alonso, A.A. \& Esser, H.J. 2019. Manihot montana, a new species of Manihot sect. Graciles (Euphorbiaceae) from the Brazilian savannas. Phytotaxa 403 (3): 210-220.

SpeciesLink. 2017. Base de dados eletrônica. Disponível em: http://www. splink.org.br. Acessado em 08.05.2017.

Thiers, B. (continuamente atualizado). 2019. Index Herbariorum: a global directory of public herbaria and associated staff. New York Botanical Garden's Virtual Herbarium. Disponível em: http://www.sweetgum. nybg.org/ih. Acessado em 14.01.2019.

Veloso, H.P., Rangel Filho, A.L.R. \& Lima, J.C.A. 1991. Classificação da vegetação brasileira, adaptada a um sistema universal. Instituto Brasileiro de Geografia e Estatística, Rio de Janeiro. 124 p.

Webster, G.L. 1994. Systematics of the Euphorbiaceae. Annals of the Missouri Botanical Garden 81: 1-144. 